\title{
Investigating the Effect of Curing and Thermal Equilibrium Time on Rutting Potential of Hot Mix Asphalt
}

\author{
Morteza Ghaffari Jajin ${ }^{1}$, Niloofar Esmaeili², Gholam Hossein Hamedi ${ }^{3^{*}}$ \\ ${ }^{1}$ Department of Civil Engineering, Islamic Azad University (Ahar Branch), P. O. B. 5451116714, Ahar, Iran \\ ${ }^{2}$ Department of Civil Engineering, Faculty of Engineering, University of Tehran, P. O. B. 131451384, Tehran, Iran \\ ${ }^{3}$ Department of Civil Engineering, Faculty of Engineering, University of Guilan, P. O. B. 3756, Rasht, Iran \\ ${ }^{*}$ Corresponding author, e-mail: hamedi@guilan.ac.ir
}

Received: 31 July 2020, Accepted: 21 January 2021, Published online: 28 January 2021

\begin{abstract}
Rutting is a common damage of flexible pavements, reducing the service life of asphalt pavement. Due to laboratory limitations, asphalt mixtures are subjected to different curing times (since construction until placement in the test chamber) and thermal equilibrium times (since placement in the test chamber until the beginning of the test) before rutting tests. Neglecting these factors can lead to errors in the laboratory results. Therefore, the present study attempted to investigate the effect of curing times of 1,2, and 3 days at $25^{\circ} \mathrm{C}$ and thermal equilibrium times of 2,4 , and 6 hours on the rutting potential of different hot-mix asphalt (HMA) mixtures. Results of rutting tests showed that the rutting potential of asphalt mixtures decreases by increasing the curing time, while the permanent deformation at the end of loading cycles and rutting potential increase by increasing the thermal equilibrium time. Additionally, the results of statistical analyses revealed that curing time and thermal equilibrium time change the rutting potential of asphalt mixtures. Keywords
\end{abstract}

hot-mix asphalt, rutting, laboratory conditions, curing time, thermal equilibrium time

\section{Introduction}

Asphalt concrete is widely used for the pavement of roads and airports. The low strength of pavements to dynamic loads is among the most important problems observed in the maintenance of highway networks $[1,2]$. Rutting, moisture damage, and fatigue cracking are three common damages caused by dynamic loads, affecting the performance of flexible pavement. Rutting or plastic deformation is one of most frequently observed distress types in the wheel paths of flexible road pavements. This distress may cause the pavement structure to be attributable to early failure by expediting the deterioration due to load and environmental detrimental agents. The loading magnitude, loading frequency, contact area, confinement condition and sample size vary for different laboratory rutting performance tests $[3,4]$. Various factors, e.g. environmental conditions (temperature), vehicle speed, tire contact pressure, and volume of passing traffic can contribute to the occurrence of this type of damage. Most rutting tests are performed at high temperatures as a major part of rutting occurs due to high thermo-sensitivity of asphalt binders and weakness in the stability of asphalt layers at high temperatures $[5,6]$.

\section{Literature review}

\subsection{Effects of laboratory conditions on warm-mix} asphalt characteristics

Al-Qadi et al. [7] investigated the effect of curing time on the dynamic modulus, fracture resistance, and indirect tensile strength of warm stone matrix asphalt (SMA). Results showed that modulus increased and fracture resistance decreased by increasing curing time. In addition, indirect tensile strength increased at first and then decreased. Moreover, $\mathrm{Wu}$ and $\mathrm{Li}$ [8] studied and compared the effect of curing time on the fatigue and thermal cracking, flow number, moisture resistance, and dynamic modulus of hotand warm-mix asphalt. Curing was performed for 2 weeks and 1 and 2 months in a closed chamber at $25^{\circ} \mathrm{C}$. Results revealed that the tensile strength ratio (TSR), flow number, dynamic modulus, and fatigue cracking resistance of specimens improved by increasing curing time and this effect was greater on warm-mix than hot-mix asphalt specimens. However, these conditions had no significant effect on the thermal cracking of specimens. Malladi et al. [9] examined the effect of curing time on the rutting resistance of warm-mix asphalt. Results indicated that, by increasing 
the curing time, rutting potential decreased in these mixes. In addition, Mogawer et al. [10] and Punith et al. [11] observed that increasing the curing time had a significant effect on the improvement of moisture resistance in hotand warm-mix asphalt.

\subsection{Effects of laboratory conditions on cold-mix asphalt characteristics}

In a study on the dynamic stability, indirect tensile strength at low temperatures and dry shrinkage of cement-emulsified asphalt mixtures, Wang et al. [12] observed that increasing the curing time improved these characteristics in the specimens. Furthermore, Guatimosim et al. [13] studied the effect of curing time on the (indirect tensile strength) ITS, rutting, and modulus of cold recycling mixture with foamed asphalt. Miljković and Radenberg [14] also investigated the effect of curing time on the ITS, rutting, and modulus of cold asphalt emulsion mixture. Both studies reported that rutting resistance decreased and modulus and ITS increased by raising curing time. Kim et al. [15] examined the impact of curing time on the ITS, flow number, and dynamic modulus of cold-in-place recycling mixtures using foamed and emulsified asphalt. Based on results, by increasing curing time, the characteristics of the two types of mixture improved. Also, in an equal time of curing, the specimen containing foamed asphalt showed a better performance than that containing asphalt emulsion. In addition, in a similar moisture percentage, the specimen containing foamed asphalt demonstrated a better performance than the one containing asphalt emulsion. Konrad and Walter [16] explored the effect of curing time on the resilient modulus and compressive strength of densegraded emulsion mixtures. They concluded that increasing the curing time increased resilient modulus and compressive strength in specimens with less than $60 \%$ moisture but had no effect on those with a higher moisture percentage.

\subsection{Effects of laboratory conditions on hot-mix asphalt characteristics}

Nguyen and Tran [17] investigated the effect of curing time on the Marshall flow and stability, rutting, and ITS of non-modified and crumb rubber-modified SMA and HMA. Curing was performed for $0,1,3$, and 5 hours in an oven at $160^{\circ} \mathrm{C}$. It was observed that, by increasing the curing time, Marshall stability and ITS increased and Marshall flow and rutting depth decreased. Moreover, Pasandín and Pérez [18] placed un-compacted HMA samples containing $0,5,10,20$, and $30 \%$ of recycled concrete aggregates in an oven for 0,2 , and 4 hours at a temperature equal to the mixing temperature of asphalt mixtures. Results showed that increasing the curing time caused an increase in the voids filled with asphalt (VFA), air voids (AV), and stiffness of specimens. In addition, the initial permanent deformation increased. Forth et al. [19] reported the effect of curing at 60,100 , and $160^{\circ} \mathrm{C}$ for $12,24,36$, and 48 hours on asphalt mixtures containing recycled materials in the form of an increase in compressive strength. Furthermore, Kliewer et al. [20] studied the effect of curing for $0,5,25$, and 100 days at 50 and $85^{\circ} \mathrm{C}$ on the low-temperature cracking of HMA mixtures and showed the reduction of fracture strength. In addition, the effect of curing time was investigated on the antistripping resistance of asphalt mixtures containing antistripping additives and the control mixture by Yoon et al. [21] results revealed an increase in stripping resistance by increasing the curing time. Mogawer et al. [10] showed that the moisture resistance of asphalt mixtures increased by increasing the curing time. Also, according to Oruc et al. [22], curing HMA specimens for 3 to 365 days at ambient temperature increased their resilient modulus. Sebaaly et al. [23] investigated the effect of curing for 2 and 4 hours at $135^{\circ} \mathrm{C}$ on HMA mixtures characteristics and reported an increase in stiffness, moisture resistance (unconfined tensile strength) and fracture temperature of thermal stress restrained specimen test following the increase in the curing time. The effect of this parameter on the rut depth measured using an asphalt pavement analyzer (APA) was not significant, but it had an increasing effect on flow number. After curing, the fatigue cracking of specimens was improved at the low-strain level, while it had no impact on the highstrain level. Das et al. [24] research demonstrated that two levels of aging conditions (short-term and long-term aged) enhanced the tensile strength and rutting resistance of bituminous mixtures while moisture conditioning reduced the rutting resistance and negatively impacted the tensile characteristics of the mixtures.

\section{Statement of the problem and objective of the study}

As observed in the literature review, most studies have examined the effect of curing time and temperature on the performance of cold- and warm-mix asphalt mixes, neglecting the susceptibility of HMA mixes to the laboratory conditions. Considering the studies conducted on the curing of HMA mixtures, it is obvious that the curing of specimens was usually performed at high temperatures or for long durations which is considered a sort of aging simulation 
indicating the focus of the majority of researches on the effect of aging on asphalt mixtures. Additionally, studies mostly concentrated on the effect of curing on the rutting of asphalt mixtures, probably because of the greater sensitivity of rutting parameter to changes of curing time.

The point largely neglected in previous studies is that specimens usually wait for medium time intervals (one to several days) prior to performing the test at laboratory temperature. Additionally, in order to reach test temperature and create thermal equilibrium, they are placed in the device for short time intervals (one to some hours) at moderate to partly high temperatures $\left(40-60^{\circ} \mathrm{C}\right)$. These two neglected parameters can lead to changes in the characteristics and performance of HMA mixtures.

Therefore, the present study explored the effect of curing time (since construction until placement in the test chamber) in the laboratory at ambient temperature (a concept of curing is different from that of previous studies) as well as thermal equilibrium time (since placement in the test chamber until running the test) on the rutting potential of HMA mixtures using RLA test. Moreover, this research investigated how the effect of curing and thermal equilibrium time on the rutting potential of asphalt mixture changes as the type of aggregate and asphalt binder changes. Three curing times $\left(1,2\right.$, and 3 days) at $25^{\circ} \mathrm{C}$, three thermal equilibrium times $\left(2,4\right.$, and 6 hours) at $40^{\circ} \mathrm{C}$, two types of asphalt binder (AC 60-70 and AC 85-100), and two types of aggregate (lime and granite) were considered in this study.

\section{Materials and laboratory program}

\subsection{Materials}

Two types of aggregate, i.e. lime and granite, were used to prepare HMA mixtures in this study to investigate the effect of curing time and thermal equilibrium time on the rutting resistance of HMA mixtures containing aggregates with different degrees of mineralogy. The compounds of minerals constituting these two types of aggregate are presented in Table 1.

The aggregates gradation for asphalt mixtures was obtained from the mean limits of ASTM specifications for dense aggregate gradation, shown in Fig. 1. The filler utilized in this research was the stone dust of the main aggregates. The physical characteristics of two types of aggregate used in this study are presented in Table 2.

In order to examine the effect of curing and thermal equilibrium time on the rutting resistance of HMA mixtures containing asphalt binder with different characteristics, two
Table 1 Compounds of minerals of two types of aggregate used in this research

\begin{tabular}{lcc}
\hline Properties & Granite (\%) & Limestone (\%) \\
\hline $\mathrm{PH}$ & 8.6 & 6.9 \\
Silicon dioxide $\left(\mathrm{SiO}_{2}\right)$ & 4.8 & 72.3 \\
$\mathrm{R}_{2} \mathrm{O}_{3}\left(\mathrm{Al}_{2} \mathrm{O}_{3}+\mathrm{Fe}_{2} \mathrm{O}_{3}\right)$ & 19 & 194 \\
Aluminum oxide $\left(\mathrm{Al}_{2} \mathrm{O}_{3}\right)$ & 1.3 & 16.7 \\
Ferric oxide, $\left(\mathrm{Fe}_{2} \mathrm{O}_{3}\right)$ & 0.7 & 1.4 \\
Magnesium oxide $(\mathrm{MgO})$ & 1.8 & 0.8 \\
Calcium oxide $(\mathrm{CaO})$ & 54.7 & 2.4 \\
\hline
\end{tabular}

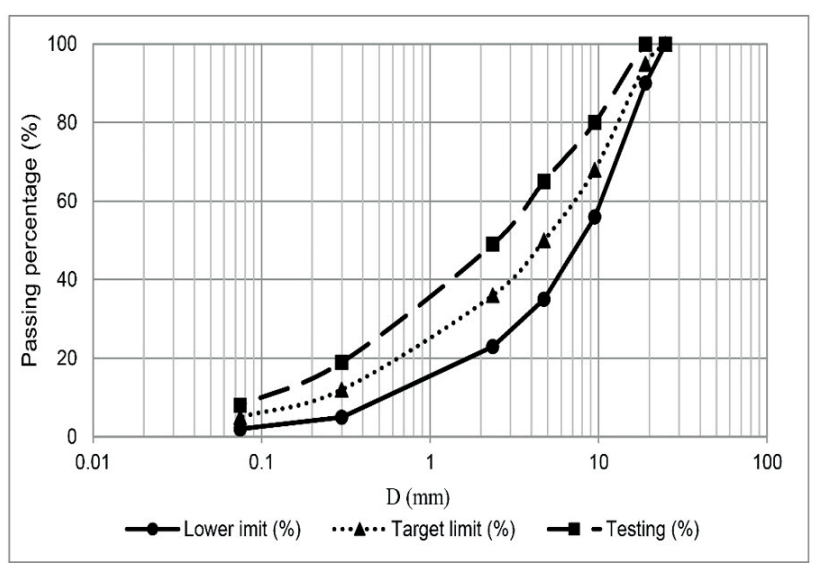

Fig. 1 Gradation of aggregates

types of asphalt binder, i.e. 60-70 and 85-100 penetration grade, were employed. Table 3 presents the physical characteristics of two types of asphalt binder used in this research.

\subsection{Laboratory program}

\subsubsection{Mixture design}

Asphalt mixtures were prepared and tested under fully controlled and standard conditions similar to field conditions as much as possible. Asphalt mixtures were prepared using the standard Marshall mix design procedure (ASTM D1559 [25]). In this method, aggregates with the temperature of $160-170^{\circ} \mathrm{C}$ and asphalt binder heated up to $135^{\circ} \mathrm{C}$ are mixed, and the mixture was compacted by 75 blows of a Marshall hammer (per side) with weight of $4.5 \mathrm{~kg}$ and the drop height of $45 \mathrm{~cm}$ on each side of the specimen. In order to determine the optimum binder content, seven binder contents $(4,4.5,5,5.5,6$, and 6.5) were utilized.

\subsubsection{Laboratory conditions}

Various laboratory conditions were applied in order to investigate the effect of curing and thermal equilibrium time on the rutting potential of HMA mixtures. To simulate curing and thermal equilibrium times, compacted 
Table 2 Physical characteristics of aggregates used in this research

\begin{tabular}{|c|c|c|c|c|}
\hline Test & Standard & Limestone & Granite & Regulation \\
\hline \multicolumn{5}{|l|}{ Coarse aggregates } \\
\hline Bulk Specific gravity, $\mathrm{g} / \mathrm{cm}^{3}$ & ASTM C 127 [26] & 2.59 & 2.61 & ----- \\
\hline SSD Specific gravity, $\mathrm{g} / \mathrm{cm}^{3}$ & & 2.60 & 2.63 & ----- \\
\hline Apparent Specific gravity, $\mathrm{g} / \mathrm{cm}^{3}$ & & 2.62 & 2.65 & ----- \\
\hline \multicolumn{5}{|l|}{ Fine aggregates } \\
\hline Bulk Specific gravity, g/cm ${ }^{3}$ & ASTM C 128 [27] & 2.57 & 2.60 & ----- \\
\hline SSD Specific gravity, $\mathrm{g} / \mathrm{cm}^{3}$ & & 2.58 & 2.62 & ----- \\
\hline Apparent Specific gravity, $\mathrm{g} / \mathrm{cm}^{3}$ & & 2.61 & 2.65 & ---- \\
\hline Specific gravity (filler), $\mathrm{g} / \mathrm{cm}^{3}$ & ASTM D854 [28] & 2.56 & 2.55 & ---- \\
\hline Los Angeles abrasion, $\%$ & ASTM C 131 [29] & 27 & 19 & At most 30 \\
\hline Water absorption, $\%$ & ASTM C127 [26] & 0.8 & 1.2 & At most 2.8 \\
\hline Flat and elongated particles, $\%$ & ASTM D 4791 [30] & 3 & 9 & At most 15 \\
\hline crushed content (two faces), $\%$ & ASTM D 5821 [31] & 89 & 91 & Based on traffic \\
\hline Sodium sulphate soundness, $\%$ & ASTM C 88 [32] & 2 & 4 & At most 8 \\
\hline Fine aggregate angularity, $\%$ & ASTM C 1252 [33] & 44.2 & 51.8 & At least 40 \\
\hline
\end{tabular}

Table 3 Physical characteristics of two types of asphalt binder used in this research

\begin{tabular}{lccc}
\hline Characteristic & Standard & AC 60-70 & AC 85-100 \\
\hline $\begin{array}{l}\text { Density @ 25 }{ }^{\circ} \mathrm{C}, \\
\text { g/cm }\end{array}$ & ASTM D7076 [34] & 1.02 & 1.03 \\
$\begin{array}{l}\text { Penetration grade } \\
\text { @ 25 }{ }^{\circ} \mathrm{C}, 0.1 \mathrm{~mm}\end{array}$ & ASTM D5-73 [35] & 66 & 91 \\
$\begin{array}{l}\text { Softening point, }{ }^{\circ} \mathrm{C} \\
\begin{array}{l}\text { Ductility @ 25 }{ }^{\circ} \mathrm{C}, \\
\text { cm }\end{array}\end{array}$ & ASTM D36-76 [36] & 51 & 48 \\
$\begin{array}{l}\text { Degree of } \\
\text { ignition, }{ }^{\circ} \mathrm{C}\end{array}$ & ASTM D92-78 [38] & 262 & 248 \\
$\begin{array}{l}\text { Weight loss, } \% \\
\text { Degree of purity, } \%\end{array}$ & ASTM D1754-78 [39] & 0.75 & 0.75 \\
\hline
\end{tabular}

specimens of each compound (lime stone and AC 60-70, granite stone and $\mathrm{AC}$ 60-70, lime stone and $\mathrm{AC} 85-100$, and granite stone and $\mathrm{AC}$ 85-100) remained at ambient temperature or at $25^{\circ} \mathrm{C}$ for 1,2 , and 3 days (curing time) and at $40^{\circ} \mathrm{C}$ for 2,4 , and 6 hours (curing equilibrium time). Therefore, there were 9 different curing conditions for each asphalt mixture. Table 4 shows the various combinations of curing conditions applied to specimens ( $\mathrm{C}$ and $\mathrm{T}$ stand for curing time and thermal equilibrium time, respectively).

\subsubsection{Repeated-load axial test}

RLA test was used to determine the rutting potential of asphalt mixtures for a long time. It is known as an adequate method for determining the rutting resistance of asphalt mixtures and employed in many research studies
Table 4 Different combinations of curing and thermal equilibrium time applied to each type of asphalt mixture

\begin{tabular}{lcc}
\hline $\begin{array}{l}\text { Abbreviated term for } \\
\text { applied condition }\end{array}$ & Curing time (day) & $\begin{array}{c}\text { Thermal equilibrium } \\
\text { time (hour) }\end{array}$ \\
\hline C1T2 & 1 & 2 \\
C1T4 & 1 & 4 \\
C1T6 & 1 & 6 \\
C2T2 & 2 & 2 \\
C2T4 & 2 & 4 \\
C2T6 & 2 & 6 \\
C3T2 & 3 & 2 \\
C3T4 & 3 & 4 \\
C3T6 & 3 & 6 \\
\hline
\end{tabular}

due to its simplicity and logical relation with permanent deformation of asphalt mixtures. The most important output of repeated-load axial test software is accumulative strain versus the number of loading cycles curve, which is somehow dependent on the rutting resistance of asphalt mixtures. Fig. 2 illustrates a sample of this curve.

Based on Fig. 2, the accumulative strain curve is generally composed of three distinct stages: (1) the primary zone in which permanent deformations are immediately accumulated on one another, (2) the secondary zone in which accumulative strains are increased with a mild and almost constant slope, and (3) the tertiary zone in which accumulative strains increase again. According to the results of FHWA-ALF Phase II test, secondary and tertiary zones occur at the end of pavement life. The three observed stages of repeated-load axial test of asphalt mixtures are exactly the same as what happens under real 


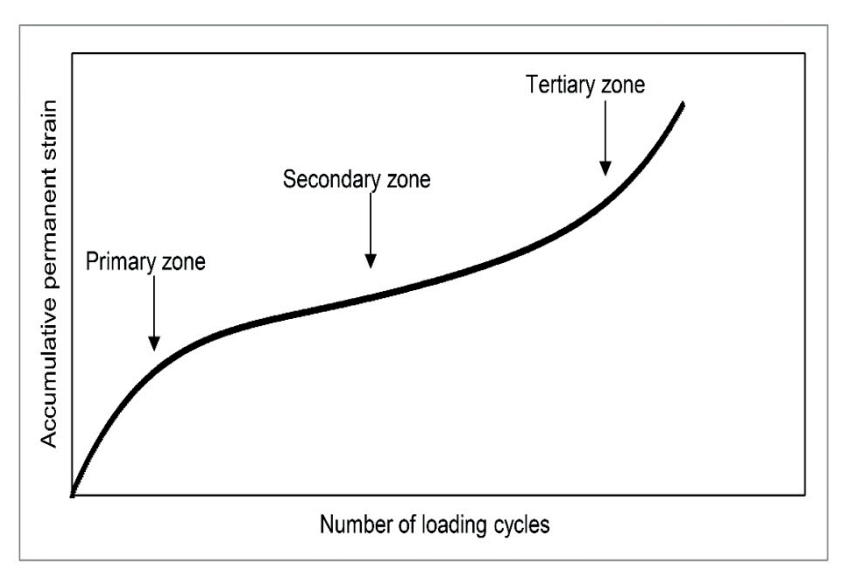

Fig. 2 The curve of accumulative strain versus the number of loading cycles

conditions. In fact, this behavior in permanent deformation (three-stage curve) is amongst the main characteristics of asphalt mixtures.

The load applied to the specimen in this test can be in different forms such as rectangular, semi-sinusoidal, or other types. Deformation is constantly measured using two LDVTs. In this research, repeated-load axial test was performed at the stress of $400 \mathrm{kPa}$ at $40^{\circ} \mathrm{C}$ using Universal Testing Machine (UTM) according to BS EN 12697-25 [41]. Conditioning stress was considered to be equal to $10 \mathrm{kPa}$ and was applied to the specimen for 10 minutes. The load was applied to the specimens for 10,000 cycles and accumulative strain was depicted as a function of load cycles.

\section{Results and discussion}

\subsection{Mix design}

Optimum binder content was determined based on the MS-2 instruction of Asphalt Institute in the following stages:

After depicting Marshall curves, corresponding binder contents were obtained as follows:

a) Binder content corresponding to maximum stability;

b) Binder content corresponding to maximum unit weight;

c) Binder content corresponding to the mean value of the $\mathrm{AV}$ interval. In this research, the $\mathrm{AV}$ interval equalled $3-5$, and 4 was selected as the average interval.

The mean of three binder contents was obtained.

For the mean binder content of the previous stage, the following parameters were obtained from Marshall curves:
a) Stability
b) Flow
c) Air void (AV)
d) Voids in the mineral aggregate (VMA)

The obtained parameters were controlled by allowed values.
The optimum binder content was calculated for all 4 types of mixtures. The type of mixtures and the optimum binder content related to each are shown in Table 5.

\subsection{Results of rutting potential tests}

Figs. 3 to 6 demonstrate the effect of curing and thermal equilibrium time on the final strains of different asphalt mixtures, mixtures constructed by limestone aggregate and 60-70 penetration grade asphalt binder, granite aggregate and 60-70 penetration grade asphalt binder, limestone aggregate and 85-100 penetration grade asphalt binder, and granite aggregate and 85-100 penetration grade asphalt binder.

Table 5 Optimum asphalt binder percentage for different samples of asphalt mixture

\begin{tabular}{lc}
\hline Mixture type & Optimum binder content (\%) \\
\hline AC 60-70 and limestone & 5.7 \\
AC 60-70 and granite stone & 5.6 \\
AC 85-100 and limestone & 5.7 \\
AC 85-100 and granite stone & 5.5 \\
\hline
\end{tabular}

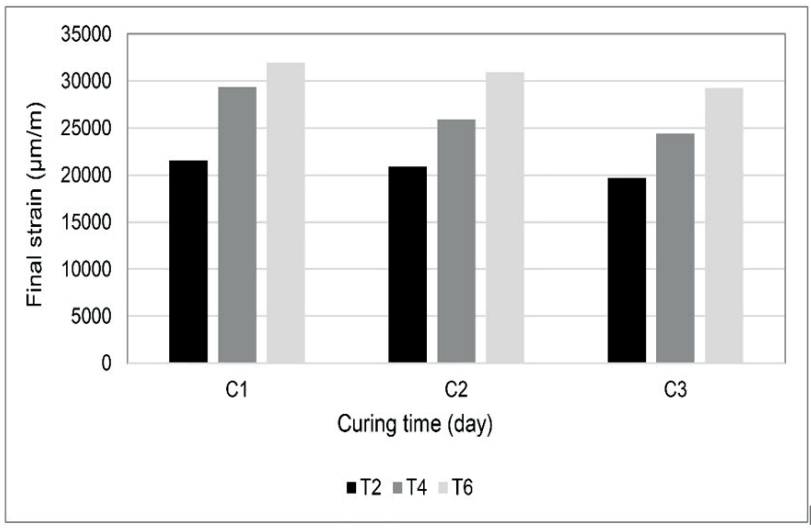

Fig. 3 The effect of curing and thermal equilibrium time on the final strain of asphalt mixtures containing limestone and 60-70 asphalt binder

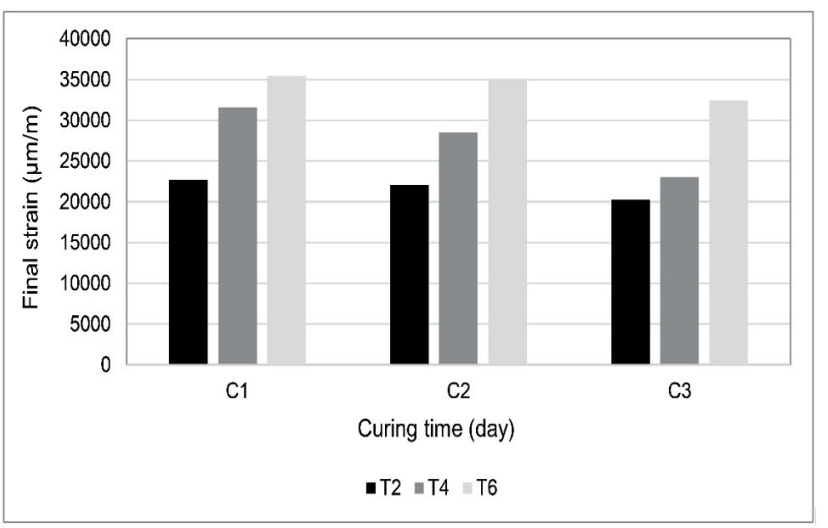

Fig. 4 The effect of curing and thermal equilibrium time on the final strain of asphalt mixtures containing limestone and 85-100 asphalt binder 


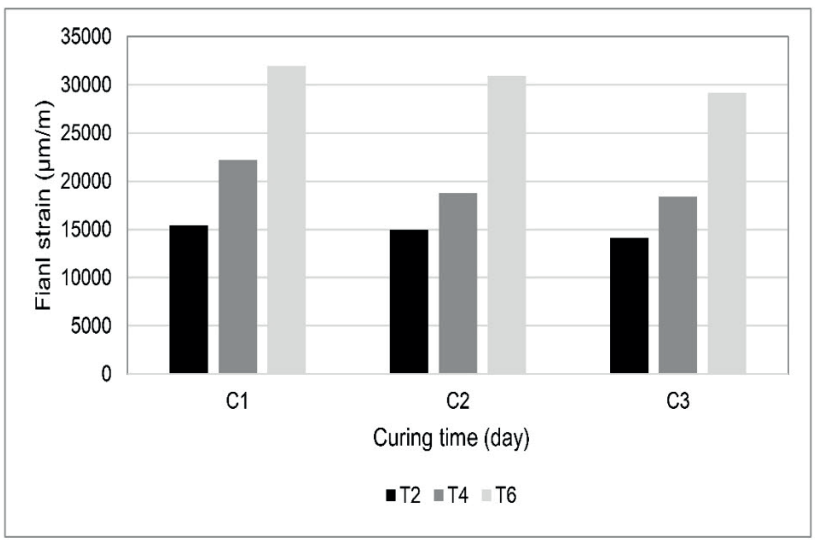

Fig. 5 The effect of curing and thermal equilibrium time on the final strain of asphalt mixtures containing granite stone and 60-70 asphalt binder

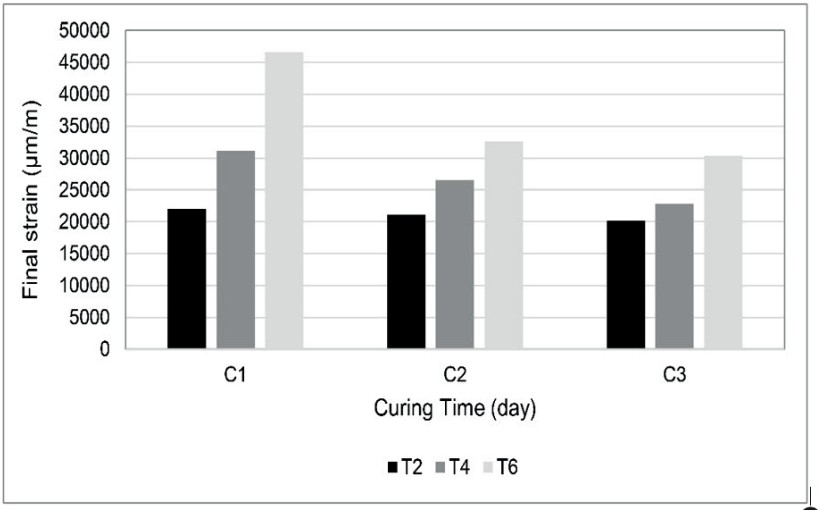

Fig. 6 The effect of curing and thermal equilibrium time on the final strain of asphalt mixtures containing granite stone and 85-100 asphalt binder

It is clear that, by increasing curing time from 1 to 3 days, the final strain of asphalt mixtures (after 10,000 cycles) decreased. This result can be related to two mechanisms, aging and strength gain of asphalt mixtures over time. A common type of aging occurring in the open air and in the presence of adequate oxygen is oxidation during which, oxygen is absorbed and hydrogen and carbon is partially removed in the form of water or carbon dioxide. As mentioned before, in this study, the curing process of the specimens was performed in the open air. Therefore, it seems that the prevailing hardening process due to aging (if exists) is directly influenced by the oxidation process rather than volatilization in asphalt binder.32. However, considering the curing conditions of specimens in this study (low temperature and approximately short time), aging probably had a negligible contribution to the increased rutting resistance of asphalt mixtures because, at low temperatures, polar molecules of asphalt binder remain highly connected and less able to react with atmospheric oxygen. Therefore, at low temperatures, polar molecules are immobilized, resulting in the quenching of the system due to low thermal energy. Moreover, the occurrence of oxidation at these temperatures, further curing days (even weeks or months) are required. The strength gain of asphalt mixtures over time is another reason for an improvement in rutting resistance. As curing time increases, the internal condition of asphalt mixtures changes, moving away from the short-term condition it had at first and reaching greater stability.7, 28. To put it differently, over time, the asphalt layer on the surface of the aggregates constituting asphalt mixtures becomes more solid, resistant and motionless, leading to higher bond strength between asphalt and aggregates and harder status of asphalt mixtures in the laboratory. Accordingly, after being placed in the test device, some heat is spent to make their initial state instable, thereby improving the rutting resistance and sliding of aggregates against one another. Considering the short time and low temperature of curing in this research, it seems that the major part of rutting resistant enhancement is caused by the strength gain made for specimens over time and only an insignificant part of it is related to asphalt mixtures' aging. The increase in the rutting resistance of asphalt mixtures by curing time progress is in agreement with the results obtained by previous research on different types of asphalt mixtures.

It was also observed that by increasing the thermal equilibrium time from 2 to 6 hours, the final strain of mixtures increased and the resistance to rutting decreased. Because when specimens are kept for some hours at average temperatures (about $40^{\circ} \mathrm{C}$ ), i.e. a temperature less than the boiling point of volatile compounds of asphalt binder, the viscosity of asphalt binder (a material which is responsible for the adhesion of aggregates in asphalt mixtures) decreases due to its thermal susceptibility. This declines the adhesion ability among aggregates of hot asphalt mixtures and makes them slide against one another when the load is applied, causing shear strains and distortions on the surface of asphalt mixtures. These effects which are known as rutting increase as the thermal equilibrium time increases. This result is inconsistent with that obtained by previous research because, in previous studies, specimens were put in the oven for short times (some hours) at high temperatures (above $100^{\circ} \mathrm{C}$ ) to simulate short-term aging that is a different type of curing. To explain this, it can be said that when specimens are exposed to high temperatures (above $100^{\circ} \mathrm{C}$ ) for several hours asphalt binder viscosity considerably increases. As asphalt is absorbed by mineral aggregates and enters the voids in the mineral aggregate 
(VMA), the amount of air in the mixture decreases and its stiffness increases. In addition, as temperature increases, at a temperature equal to the boiling point of the volatile compounds of asphalt binder, binder volatile fractions are separated, the percentage of asphaltenes to maltenes increases, and short aging occurs in the asphalt binder, leading to asphalt hardening and increased rutting resistance.

Fig. 7 shows the final strain of different asphalt mixtures after being subjected to different curing and thermal equilibrium times. It is clear how rutting potential changes as aggregate and asphalt binder type changes.

It is clear that mixtures with granite aggregates exhibited a higher resistance to rutting compared to those with lime aggregates because of the physical characteristics of aggregates. As shown in Table 2, in the present research, granite aggregates had a higher crushed content and angularity compared to lime aggregates, thereby might cause an increase in the strength of aggregates' reliance on one another and improving the aggregates interlocking. In fact, the texture of granite aggregates was such that it led to the formation of a physical bonding mechanism superior to limestone aggregates in asphalt mixtures.

The asphalt binder affects different functional aspects of asphalt mixtures such as permanent deformation, fatigue cracking, and low-temperature cracking. The type and characteristics of binder should be selected in such a way that its effect on pavement performance would be optimal and appropriate to certain conditions. At normal temperatures, asphalt binder exhibits the characteristics of both viscous liquids and elastic solids. Asphalt binder with a higher penetration grade has lower viscosity and hardness and exhibits greater thermal sensitivity in comparison to one with a lower penetration grade. Therefore, in asphalt binder with a lower penetration grade, the performance

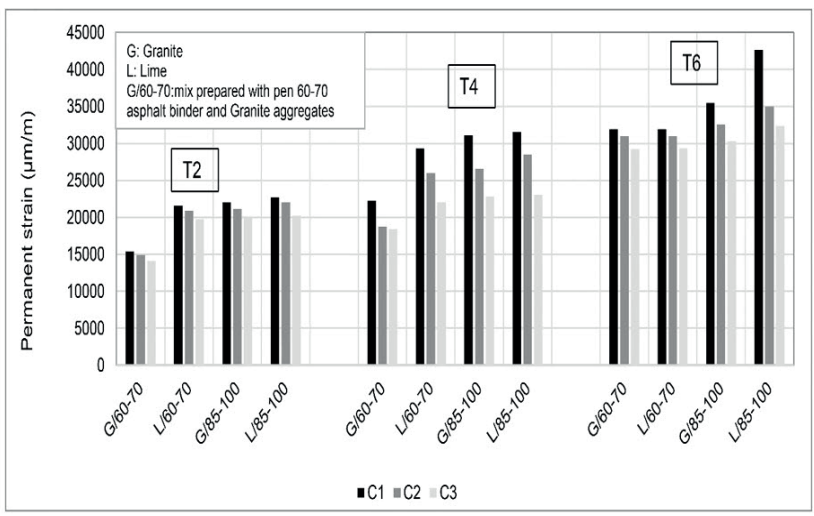

Fig. 7 Permanent strain for different asphalt mixtures under different laboratory conditions of the elastic component is better than that of the viscose component and a greater part of deformation returns to its original state and a smaller part remains deformed during load application. At an equal temperature, the 85-100 asphalt binder shows less viscosity and stiffness compared to the 60-70 asphalt binder and establishes a weaker bond with and among aggregates. Therefore, asphalt mixtures containing a higher penetration grade asphalt binder show less resistance to pressure (rutting) at functional temperatures, as can be seen in Fig. 7.

In addition, it can be seen that the effect of thermal equilibrium and curing time on the rutting potential of specimens containing AC 60-70 asphalt binder was less than that of the specimen containing AC 85-100 asphalt binder. Moreover, specimens constructed by granite aggregates showed less sensitivity to thermal equilibrium and curing time in comparison to those containing lime aggregates. These are precisely related to the difference in the nature and chrematistics of different asphalts binders and aggregates, affecting rutting as mentioned above. Maximum rutting resistance was observed for the mixtures containing 60-70-penetration grade asphalt binder and granite aggregates and the minimum belonged to the mixtures containing 85-100-penetration grade asphalt binder and lime aggregates.

\subsection{Statistical analysis of curing and thermal equilibrium time}

In order to determine whether the effect of curing and thermal equilibrium time on the rutting potential of HMA mixtures is notable or not, statistical analyses were performed separately for each type of asphalt mixture. Two independent variables of these analyses included curing time and thermal equilibrium time and the dependent variable was permanent deformation at the end of 10,000 cycles. In the table of variables, C, T, and PD stand for curing time, thermal equilibrium time, and permanent deformation, respectively. The results of statistical analysis for different asphalt mixtures are listed in Table 6.

The first row of Table 6 demonstrates the statistical analysis of asphalt mixtures containing lime aggregates and 60-70 asphalt binder. It shows that the values of sig column related to $\mathrm{C}$ and $\mathrm{T}$ variables are less than 0.05 . It means that the independent variables of this research have a significant effect on the dependent variable. Results of the unstandardized coefficients column show that permanent deformation decreases by increasing curing time and permanent deformation increases by increasing thermal equilibrium time. Additionally, according to the values of 
Table 6 Statistical analysis of permanent deformation of the mixtures containing lime aggregates and 60-70 asphalt binder

\begin{tabular}{|c|c|c|c|c|c|c|}
\hline \multirow{2}{*}{ Mixture type } & \multirow{2}{*}{ Model } & \multicolumn{2}{|c|}{ Unstandardized Coefficients } & \multirow{2}{*}{$\begin{array}{c}\text { Standardized Coefficients } \\
\text { Beta }\end{array}$} & \multirow[t]{2}{*}{$\mathrm{t}$} & \multirow[t]{2}{*}{ sig. } \\
\hline & & $\mathrm{B}$ & Std. Error & & & \\
\hline \multirow{3}{*}{$\begin{array}{l}\text { Lime aggregate and } \\
\text { binder } 60-70\end{array}$} & (Constant) & 19688.180 & 1454.837 & & 13.533 & .000 \\
\hline & $\mathrm{C}$ & -1972.568 & 494.183 & -.358 & -3.992 & .007 \\
\hline & $\mathrm{T}$ & 2498.876 & 247.092 & .907 & 10.113 & .000 \\
\hline \multirow{3}{*}{$\begin{array}{l}\text { Lime aggregate and } \\
\text { binder } 85-100\end{array}$} & (Constant) & 19937.849 & 1783.245 & & 11.181 & .000 \\
\hline & $\mathrm{C}$ & -2330.636 & 605.738 & -.339 & -3.848 & .008 \\
\hline & $\mathrm{T}$ & 3152.521 & 302.869 & .916 & 10.409 & .000 \\
\hline \multirow{3}{*}{$\begin{array}{l}\text { Granite aggregate and } \\
\text { binder } 60-70\end{array}$} & (Constant) & 8476.320 & 2245.706 & & 3.774 & .009 \\
\hline & $\mathrm{C}$ & -1298.444 & 762.829 & -.157 & -1.702 & .040 \\
\hline & $\mathrm{T}$ & 3973.581 & 381.414 & .961 & 10.418 & .000 \\
\hline \multirow{3}{*}{$\begin{array}{l}\text { Granite aggregate and } \\
\text { binder } 85-100\end{array}$} & (Constant) & 21558.407 & 4479.932 & & 4.812 & .003 \\
\hline & $\mathrm{C}$ & -4409.662 & 1521.757 & -.458 & -2.898 & .027 \\
\hline & $\mathrm{T}$ & 3852.017 & 760.879 & .800 & 5.063 & .002 \\
\hline
\end{tabular}

sig column, the value related to the thermal equilibrium time is closer to zero, meaning that this parameter affects the results of repeated-load axial test more considerably compared to the curing time parameter.

The second row of Table 6 presents the statistical analysis related to the effect of curing and thermal equilibrium time on the rutting potential of mixtures containing 85-100-penetration grade asphalt binder and limestone aggregates. The standardized coefficient values for $\mathrm{C}$ and $\mathrm{T}$ equalled -0.339 and +0.916 , respectively. Considering the negative coefficient for $\mathrm{C}$ and positive coefficient for $\mathrm{T}$, it can be inferred that increasing the curing time causes a reduction in the permanent deformation and increasing thermal equilibrium time causes an increase in the permanent deformation and rutting potential of asphalt mixtures. Values less than 0.05 in the sig column indicate the significant effect of these two parameters $(\mathrm{C} \& \mathrm{~T})$ on permanent deformation. Similar to specimens constructed by lime aggregates and 60-70 asphalt binder, the effect of thermal equilibrium time is greater than that of curing time on the results of permanent deformation of asphalt mixtures in this group.

The third row of Table 6 exhibits the results of statistical analysis conducted on the effect of curing and thermal equilibrium time on the rutting potential of asphalt mixtures constructed by 60-70-penetration grade asphalt binder and granite aggregates. The results show that curing and thermal equilibrium time significantly affect permanent deformation. Based on the unstandardized coefficients column, permanent deformation decreases by increasing curing time and permanent deformation increases by increasing thermal equilibrium time. Additionally, the results of sig column show that thermal equilibrium time can more effectively change the results of repeated-load axial test.

The final row of Table 6 indicates the results of statistical analysis of mixtures containing granite aggregates and 85-100-penetration grade asphalt binder. Similar to the previous three groups, the effect of two independent parameters on the dependent parameter is evident. The standardized coefficients of curing and thermal equilibrium time are negative and positive, respectively. This means that an increase in these two parameters causes a reduction and an increase in the permanent deformation of asphalt mixtures, respectively.

\section{Conclusions}

Permanent deformation is one of the major load-related failures of asphalt mixtures, affecting the performance of asphalt pavement. Rutting in an asphalt layer occurs due to structural deficiencies in the solid phase (aggregate) or binder phase (asphalt). The rutting of asphalt mixtures is affected by a variety of factors, namely curing time, thermal equilibrium time, type of binder, and characteristics of mineral aggregates. The present study explored the effect of curing and thermal equilibrium time on the rutting potential of HMA mixtures using repeated-load axial test by manufacturing different types of asphalt mixtures (using two types of asphalt binder, AC 60-70 and AC 85-100, and two types of aggregate, lime and granite) and subjecting them to different conditions of curing and thermal equilibrium times. The curing times of 1,2 , and 3 days at $25^{\circ} \mathrm{C}$ and thermal equilibrium times of 2, 4, and 6 hours constituted the variables. Based on the findings and analyses, the following results were obtained: 
- By increasing the curing time from 1 to 3 days, the rutting resistance of asphalt mixtures was increased under the effect of aging and strength gaining over time. The passage of time makes the mixtures reach a stiffer status. Consequently, after being placed in the test device, some heat is spent to make their initial state instable, thereby increasing their resistance to rutting. Considering the short time and low temperature of curing in this research, the effect of aging on the rutting resistance of asphalt mixtures can be considered insignificant compared to strength gaining over time. In fact, the probability of aging is very low at this duration and temperature.

- By increasing the thermal equilibrium time, the permanent deformation or rutting of asphalt mixtures was increased. This was evident for all 4 asphalt mixtures. In fact, by placing specimens into the oven at average temperatures $\left(40^{\circ} \mathrm{C}\right)$ for short durations (2-6 hours), the viscosity of asphalt binder and the adhesion ability among aggregates decreases and the probability of shear strains and rutting of asphalt mixtures increases. The thermal equilibrium time of 6 hours caused all asphalt mixture specimens to enter the third phase of creep behavior.

- The results of the statistical analyses of permanent deformation of different asphalt mixtures showed that curing and thermal equilibrium time can significantly affect the permanent deformation of asphalt mixtures. Permanent deformation decreases by increasing the curing time and increases by increasing the thermal equilibrium time. Additionally, it was found that thermal equilibrium time more effectively affect the permeant deformation of asphalt mixtures (obtained from the RLA test) compared to curing time.

- In comparison to specimens constructed by limestone aggregates and 85-100-penetration grade asphalt binder, those constructed by granite aggregates and 60-70-penetration grade asphalt binder showed less susceptibility to an increase in thermal equilibrium and curing time, indicating less rutting potential of these mixtures. This is due to the greater crushing and angularity of granite aggregates

\section{References}

[1] Sohrabi, M., Shirmohammadi, H., Hamedi, G. H. "Investigating the Effect of Modifying Aggregate Surface by Micronized Calcium Carbonate on Increasing the Moisture Resistance of Asphalt Mixtures", Periodica Polytechnica Civil Engineering, 63(1), pp. 63-76, 2019.

https://doi.org/10.3311/PPci.11632 compared to lime aggregates used in this research and higher viscosity and stiffness of asphalt binder, leading to higher elastic performance of lower penetration grade asphalt binders.

- Generally, specimens are not tested immediately after construction and different specimens are tested at different times after construction. Lack of attention to these times (when, after construction and exiting from the mold, the specimen waits to be tested and the duration in which the specimen remains in the test chamber in order to reach thermal equilibrium) increases the probability of making a mistake in the laboratory study of rutting performance of asphalt mixtures, leading to a lack of coordination and integration among different specimens which are constructed to be compared to one another.

The characteristics of asphalt mixtures vary over time. Moreover, laboratory tests are performed to assess mixture performance during service life and over time. Therefore, it seems that the specimens are required to remain in the laboratory for some time after compaction and then be tested. Finding the optimal time for curing and thermal equilibrium is of paramount importance, reducing mistakes and the inconsistency between field and laboratory test results. In order to obtain these optimal times, it is necessary to investigate broader time intervals than those discussed in this study. In addition, this optimal time is different for different tests and must be calculated for each test procedure. Future studies can conduct a broader assessment of the effect of laboratory conditions such as storage time of the binder in the oven prior fabricating the specimen; the mixing, construction, and compaction method; the presence or absence of moisture and its percentage in the atmosphere; and the effect of light on the mechanical properties of asphalt mixtures. In addition, determining optimal curing conditions and providing a solution to minimize and equate the effect of these laboratory conditions on the construction and testing of different asphalt mixtures can be introduced as suggestions for further studies.

[2] Hamedi, G. H., Azarhoosh, A. R., Khodadadi, M. "Effects of Asphalt Binder Modifying with Polypropylene on Moisture Susceptibility of Asphalt Mixtures with Thermodynamically Concepts", Periodica Polytechnica Civil Engineering, 62(4), pp. 901-910, 2018.

https://doi.org/10.3311/PPci.11570 
[3] Choudhary, R., Kumar, A., Murkute, K. "Properties of Waste Polyethylene Terephthalate (PET) Modified Asphalt Mixes: Dependence on PET Size, PET Content, and Mixing Process", Periodica Polytechnica Civil Engineering, 62(3), pp. 685-693, 2018. https://doi.org/10.3311/PPci.10797

[4] Azarhoosh, A. R., Hamedi, G. H., Abandansari, H. F. "Providing Laboratory Rutting Models for Modified Asphalt Mixes with Different Waste Materials", Periodica Polytechnica Civil Engineering, 62(2), pp. 308-317, 2018. https://doi.org/10.3311/PPci.10684

[5] Bargegol, I., Sakanlou, F., Sohrabi, M., Hamedi, G. H. "Investigating the Effect of Metal Nanomaterials on the Moisture Sensitivity Process of Asphalt Mixes", Periodica Polytechnica Civil Engineering, 65(1), pp. 15-25, 2021. https://doi.org/10.3311/PPci.12223

[6] Hamedi, G. H., Shabani, A., Safargar, Y. "Investigating the Effect of Hydrophobic Additives in Moisture Damage Reduction of Asphalt Mixtures", Periodica Polytechnica Civil Engineering, 64(3), pp. 702-712, 2020.

https://doi.org/10.3311/PPci.15457

[7] Al-Qadi, I. L., Wang, H., Baek, J., Leng, Z., Doyen, M., Gillen, S. "Effects of Curing Time and Reheating on Performance of Warm Stone-Matrix Asphalt", Materials in Civil Engineering, 24(11), pp. 1422-1428, 2012.

https://doi.org/10.1061/(ASCE)MT.1943-5533.0000513

[8] Wu, S., Li, X. "Evaluation of effect of curing time on mixture performance of Advera warm mix asphalt", Construction and Building Materials, 145, pp. 62-67, 2017.

https://doi.org/10.1016/j.conbuildmat.2017.03.240

[9] Malladi, H., Ayyala, D., Tayebali, A. A., Khosal, N. P. "Laboratory Evaluation of Warm-Mix Asphalt Mixtures for Moisture and Rutting Susceptibility", Materials in Civil Engineering, 27(5), Article No. 04014162, 2014.

https://doi.org/10.1061/(ASCE)MT.1943-5533.0001121

[10] Mogawer, W. S., Austerman, A. J., Bahia, H. U. "Evaluating the Effect of Warm-Mix Asphalt Technologies on Moisture Characteristics of Asphalt Binders and Mixtures", Transportation Research Record, 2209(1), pp. 52-60, 2011. https://doi.org/10.3141/2209-07

[11] Punith, V. S., Xiao, F., Putman, B., Amirkhanian, S. N. "Effects of long-term aging on moisture sensitivity of foamed WMA mixtures containing moist aggregates", Materials and Structures, 45, pp. 251264, 2011

https://doi.org/10.1617/s11527-011-9763-4

[12] Wang, Z., Wang, Q., Ai, T. "Comparative study on effects of binders and curing ages on properties of cement emulsified asphalt mixture using gray correlation entropy analysis", Materials and Structures, 54, pp. 615-622, 2014.

https://doi.org/10.1016/j.conbuildmat.2013.12.093

[13] Guatimosim, F. V., Vasconcelos, K. L., Bernucci, L. L. B., Jenkins, K. J. "Laboratory and field evaluation of cold recycling mixture with foamed asphalt", Road Materials and Pavement Design, 19(2), pp. 385-399, 2018.

https://doi.org/10.1080/14680629.2016.1261726
[14] Miljković, M., Radenberg, M. "Characterising the influence of bitumen emulsion on asphalt mixture performance", Materials and Structures, 48, pp. 2195-2210, 2015. https://doi.org/10.1617/s11527-014-0302-y

[15] Kim, Y., Im, S., Lee, H. D. "Impacts of Curing Time and Moisture Content on Engineering Properties of Cold In-Place Recycling Mixtures Using Foamed or Emulsified Asphalt", Materials in Civil Engineering, 23(5), pp. 542-553, 2011. https://doi.org/10.1061/(ASCE)MT.1943-5533.0000209

[16] Konard, J.-M., Walter, J. "Influence of Curing on the Mechanical Properties of a Dense Graded Emulsion Mix", Road Materials and Pavement Design, 2(2), pp. 181-194, 2001. https://doi.org/10.1080/14680629.2001.9689899

[17] Nguyen, H. T. T., Tran, T. N. "Effects of crumb rubber content and curing time on the properties of asphalt concrete and stone mastic asphalt using dry process", International Journal of Pavement Research and Technology, 11, pp. 236-244, 2018. https://doi.org/10.1016/j.ijprt.2017.09.014

[18] Pasandín, A. R., Pérez, I. "Effect of ageing time on properties of hotmix asphalt containing recycled concrete aggregates", Construction and Building Materials, 52, pp. 284-293, 2014. https://doi.org/10.1016/j.conbuildmat.2013.11.050

[19] Forth, J. P., Dao, D. V., Zoorob, S. E. "Investigating the Effects of Curing Methods on the Compressive Strength of Bitublock", Journal of Materials in Civil Engineering, 22(3), pp. 207-213, 2010. https://doi.org/10.1061/(ASCE)0899-1561(2010)22:3(207)

[20] Kliewer, J. E., Zeng, H., Vinson, T. S. "Aging and Low-Temperature Cracking of Asphalt Concrete Mixture", Journal of Cold Regions Engineering, 10(3), pp. 134-148, 1996. https://doi.org/10.1061/(ASCE)0887-381X(1996)10:3(134)

[21] Yoon, H. H., Tarrer, A. R., Wagh, V. P. "Thermal Degradation of Antistripping Agents and Enhanced Performance by Curing", Journal of Materials in Civil Engineering, 5(1), pp. 1-18, 1993. https://doi.org/10.1061/(ASCE)0899-1561(1993)5:1(1)

[22] Oruc, S., Celik, F., Akpinar, M. V. "Effect of Cement on Emulsified Asphalt Mixtures", Journal of Materials Engineering and Performance, 16, pp. 578-583, 2007. https://oi.org/10.1007/s11665-007-9095-2

[23] Sebaaly, P. E., Hajj, E. Y., Piratheepan, M. "Evaluation of selected warm mix asphalt technologies", Road Materials and Pavement Design, 16(sup1), pp. 475-486, 2015. https://doi.org/10.1080/14680629.2015.1030825

[24] Das, B., Bhargava, N., Siddagangaiah, A. "Influence of Environmental Conditions on the Performance of Bituminous Mixtures", Advances in Civil Engineering Materials, 7(2), pp. 163-180, 2018. https://doi.org/10.1520/ACEM20170091

[25] ASTM "ASTM D1559-89 Test Method for Resistance of Plastic Flow of Bituminous Mixtures Using Marshall Apparatus", ASTM International, West Conshohocken, PA, USA, 1989.

[26] ASTM "ASTM C127 - 15 Standard Test Method for Relative Density (Specific Gravity) and Absorption of Coarse Aggregate", ASTM International, West Conshohocken, PA, USA, 2015. https://doi.org/10.1520/C0127-15 
[27] ASTM "ASTM C128 - 15 Standard Test Method for Relative Density (Specific Gravity) and Absorption of Fine Aggregate", ASTM International, West Conshohocken, PA, USA, 2015. https://doi.org/10.1520/C0128-15

[28] ASTM "ASTM D854 - 14 Standard Test Methods for Specific Gravity of Soil Solids by Water Pycnometer", ASTM International, West Conshohocken, PA, USA, 2014. https://doi.org/10.1520/D0854-14

[29] ASTM "ASTM C131 - 01 Standard Test Method for Resistance to Degradation of Small-Size Coarse Aggregate by Abrasion and Impact in the Los Angeles Machine", ASTM International, West Conshohocken, PA, USA, 2001.

[30] ASTM "ASTM D4791 - 19 Standard Test Method for Flat Particles, Elongated Particles, or Flat and Elongated Particles in Coarse Aggregate", ASTM International, West Conshohocken, PA, USA, 2019 https://doi.org/10.1520/D4791-19

[31] ASTM "ASTM D5821 - 13 Standard Test Method for Determining the Percentage of Fractured Particles in Coarse Aggregate", ASTM International, West Conshohocken, PA, USA, 2017. https://doi.org/10.1520/D5821-13R17

[32] ASTM "ASTM C88 - 13 Standard Test Method for Soundness of Aggregates by Use of Sodium Sulfate or Magnesium Sulfate", ASTM International, West Conshohocken, PA, USA, 2013. https://doi.org/10.1520/C0088-13

[33] ASTM "ASTM C1252 - 17 Standard Test Methods for Uncompacted Void Content of Fine Aggregate (as Influenced by Particle Shape, Surface Texture, and Grading)", ASTM International, West Conshohocken, PA, USA, 2017. https://doi.org/10.1520/C1252-17
[34] ASTM "ASTM D7076 - 10 Standard Test Method for Measurement of Shives in Retted Flax", ASTM International, West Conshohocken, PA, USA, 2010 https://doi.org/10.1520/D7076-10

[35] ASTM "ASTM D5 - 73(1978) Standard Test Method for Penetration Of Bituminous Materials", ASTM International, West Conshohocken, PA, USA, 1978.

[36] ASTM "ASTM D36 - 76 Standard Test Method for Softening Point Of Bitumen (Ring-And-Ball Apparatus)", ASTM International, West Conshohocken, PA, USA, 1976.

[37] ASTM "ASTM D113 - 79 Standard Test Method for Ductility of Asphalt Materials", ASTM International, West Conshohocken, PA, USA, 1979.

[38] ASTM "ASTM D92 - 78 Standard Test Method for Flash and Fire Points by Cleveland Open Cup Tester", ASTM International, West Conshohocken, PA, USA, 1978.

[39] ASTM "ASTM D1754 - 78 Standard Test Method for Effects of Heat and Air on Asphaltic Materials (Thin-Film Oven Test)", ASTM International, West Conshohocken, PA, USA, 1978.

[40] ASTM "ASTM D2042 - 76 Standard Test Method for Solubility of Asphalt Materials in Trichloroethylene", ASTM International, West Conshohocken, PA, USA, 1976. https://doi.org/10.1520/D1559-89

[41] BSI "BS EN 12697-25:2016 Bituminous mixtures. Test methods. Cyclic compression test", British Standards Institution, London, UK, 2016. 